University of Nebraska - Lincoln

DigitalCommons@University of Nebraska - Lincoln

Gordon Gallup Publications

Research Papers in Physics and Astronomy

May 1952

\title{
Chemical Reactions near Equilibrium
}

W.R. Gilkerson

University of Kansas - Lawrence

M.M. Jones

University of Kansas - Lawrence

Gordon A. Gallup

UNL,ggallup1@unl.edu

Follow this and additional works at: https://digitalcommons.unl.edu/physicsgallup

Part of the Physics Commons

Gilkerson, W.R.; Jones, M.M.; and Gallup, Gordon A., "Chemical Reactions near Equilibrium" (1952). Gordon Gallup Publications. 31.

https://digitalcommons.unl.edu/physicsgallup/31

This Article is brought to you for free and open access by the Research Papers in Physics and Astronomy at DigitalCommons@University of Nebraska - Lincoln. It has been accepted for inclusion in Gordon Gallup Publications by an authorized administrator of DigitalCommons@University of Nebraska - Lincoln. 


\section{Chemical Reactions near Equilibrium}

W. R. Gilkerson, M. M. Jones,† and G. A. Gallup* University of Kansas, Lawrence, Kansas (Received May 1, 1952)

T $\mathrm{N}$ seeming contradiction to usual deductions from thermodynamics, it has been shown by De Donder ${ }^{1}$ on the basis of his affinity function, by Prigogine ${ }^{2}$ on the basis of the ChapmanEnskog model, and by Manes, Hofer, and Weller ${ }^{3}$ using purely mathematical methods, that the rate of a chemical reaction close to equilibrium is directly proportional to the free energy difference between reactants and products. This relation may be shown to be a consequence of the theory of absolute reaction rates, also.

If one has the generalized reaction

$$
\begin{gathered}
A+B+\cdots \neq M+N+\cdots, \\
\Delta F_{f}^{\ddagger}=\Delta F_{f}^{\ddagger 0}+R T \ln Q_{f}^{\ddagger}=\Delta F_{f}^{\ddagger 0}+R T \ln \frac{a^{\ddagger}}{a_{A} a_{B} \cdots} \\
\Delta F_{r}^{\ddagger}=\Delta F_{r}^{\ddagger 0}+R T \ln Q_{r}^{\ddagger}=\Delta F_{r}^{\ddagger 0}+R T \ln \frac{a^{\ddagger}}{a_{M} a_{N} \cdots},
\end{gathered}
$$

where $\Delta F_{f} \ddagger$ is the free energy of activation of the forward reaction at any concentration, $\Delta F_{r} \ddagger$ is the free energy of activation of the reverse reaction at any concentration, $\Delta F_{f} t^{\circ}$ is the standard free energy of activation of the forward reaction, and $\Delta F_{r}{ }^{t 0}$ is the standard free energy of activation for the reverse reaction. $a_{i}$ is the activity of the $i$ th component and $a^{\ddagger}$ is the activity of the activated complex.

We may now write the expressions for the rate constants of the forward and reverse reactions as

$$
\begin{aligned}
k_{f} & =\kappa_{f} \frac{k T}{h} \exp \left(-\frac{\Delta F_{f}^{\ddagger 0}}{R T}\right) ; & k_{r}=\kappa_{r} \frac{k T}{h} \exp \left(-\frac{\Delta F_{r}{ }^{\ddagger 0}}{R T}\right) \\
& =\kappa_{f} \frac{k T}{h} Q_{f}^{\ddagger} \exp \left(-\frac{\Delta F_{f}^{\ddagger}}{R T}\right) ; & =\kappa_{r} \frac{k T}{h} Q_{r}^{\ddagger} \exp \left(-\frac{\Delta F_{r}^{\ddagger}}{R T}\right) .
\end{aligned}
$$

The expression for the rate of this reaction becomes

$$
\begin{aligned}
\frac{d a_{A}}{d t}=\frac{d a_{B}}{d t}=\cdots & =-\frac{d a_{M}}{d t}=-\frac{d a_{N}}{d t}=\cdots \\
& =k_{f} a_{A} a_{B} \cdots-k_{F} a_{M} a_{N} \cdots .
\end{aligned}
$$

If we assume that $\kappa_{f}=\kappa_{r}$

$$
\begin{aligned}
\frac{d a_{A}}{d t} & =\kappa \frac{k T}{h} a^{\ddagger}\left[\exp \left(-\frac{\Delta F_{f}^{\ddagger}}{R T}\right)-\exp \left(-\frac{\Delta F_{t}^{\dagger}}{R T}\right)\right] \\
& =\kappa \frac{k T}{h} a^{\ddagger} \sum_{n=0}^{\infty} \frac{1}{n !}\left[\left(-\frac{\Delta F_{f}^{+}}{R T}\right)^{n}-\left(-\frac{\Delta F_{r}^{\dagger}}{R T}\right)^{n}\right] .
\end{aligned}
$$

If the reaction is close enough to equilibrium, $\Delta F_{f}^{\ddagger} / R T \ll 1$, $\Delta F_{\mathbf{r}} \ddagger / R T \ll 1$, and

$$
\begin{aligned}
\frac{d a_{A}}{d l} & \simeq \kappa \frac{k T}{h} \frac{a \ddagger}{R T}\left(\Delta F_{F} \ddagger-\Delta F_{f} \ddagger\right) \\
& \cong \frac{k a^{\ddagger}}{h N} \Delta F_{3}
\end{aligned}
$$

where $\Delta F=\Delta F_{5}+-\Delta F_{f} \neq$ and $N$ is Avogadro's number. This approximation also becomes better as the temperature becomes higher.

Near equilibrium, $a^{t}$ will be approximately constant and the rate becomes directly proportional to the free energy change.

It is to be noted that this development indicates such behavior only in the limit. Some experimental results in the literature support this contention. This development also indicates that attempts to apply this treatment to the kinetics of reactions not very close to equilibrium will not be successful.

The most useful form of the absolute reaction rate theory involves the Gibbs free energy. However, as Manes et al., show, the mathematical analysis can be carried out for any thermodynamic state function. So long as the conditions on the reaction are appropriate, any state function may be used in the absolute reaction rate theory to obtain results analogous to those of Manes.

* AEC Predoctoral Fellow.

† du Pont Fellow.

2 I. Prigogine, Etude thermodynamique des phenomenes irreversibles (Desoer, Leige, Belgium, 1947)

${ }^{3}$ Manes, Hofer, and Weller, J. Chem. Phys. 18, 1355 (1950). 